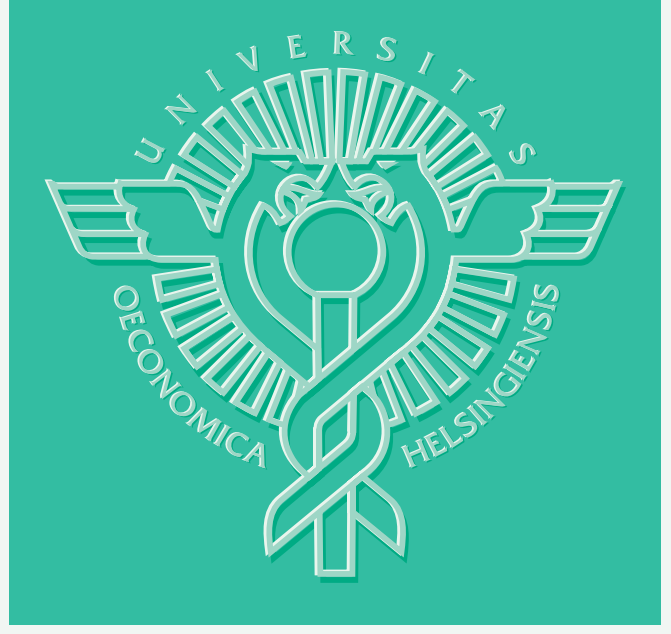

Pekka Korhonen - Raimo Voutilainen

\title{
FINDING THE MOST PREFERRED ALLIANCE STRUCTURE BETWEEN BANKS AND INSURANCE COMPANIES
}


Pekka Korhonen - Raimo Voutilainen

\title{
FINDING THE MOST PREFERRED ALLIANCE STRUCTURE BETWEEN BANKS AND INSURANCE COMPANIES
}

\author{
Quantitative Methods in Economics and \\ Management Science
}

April

2004 
HELSINGIN KAUPPAKORKEAKOULU

HELSINKI SCHOOL OF ECONOMICS

PL 1210

FIN-00101 HELSINKI

FINLAND

Pekka Korhonen

Helsinki School of Economics

Runeberginkatu 14-16, 00100 Helsinki, Finland

Email: pekka.korhonen@hkkk.fi

Raimo Voutilainen

Helsinki, Finland

Email: r.voutilainen@kolumbus.fi

The research was supported, in part, by grants from the Academy of Finland.

All rights reserved. This study may not be reproduced in whole or in part without the authors' permission.

(C) Pekka Korhonen, Raimo Voutilainen and

Helsinki School of Economics

ISSN 1235-5674

ISBN 951-791-847-X (Electronic working paper)

Helsinki School of Economics -

HeSE print 2004 


\begin{abstract}
In this paper we have studied alternative alliances between banks and insurance companies. First we defined six different possible structure models for such alliances, and nine criteria used to evaluate the models. The models and the criteria were introduced together with bank and insurance experts. The experts are representatives of the top management of Finnish banks and insurance companies. Searching for the most preferred alliance model is a multiple criteria decision making (MCDM) problem. To solve the problem, we used an expert panel and the Analytic Hierarchy Process (AHP). Based on the evaluations of the panel, the alternatives Financial Conglomerate and Cross-Selling Agreement, no Overlapping Service Channels are most preferred. Which one is chosen, depends on how risk is emphasized.
\end{abstract}

Keywords: Financial alliances, financial conglomerates, multiple criteria decision making, Analytic Hierarchy Process, strategic planning

\title{
1 Introduction
}

Alliance formation has been a growing trend among the financial industry during the last decades. The insurers in an alliance can be life and/or non-life companies. Alliances between banks and non-life insurance companies with no life counterparts are in practice rare. On the other hand, synergies between retail banking and life insurance are so significant that one often encounters alliances between banks and life insurers without non-life counterparts.

Financial alliances often include units like mutual fund managing companies, asset management companies, securities brokerages and corporate finance companies. In most European countries banks are allowed to be "universal". Consequently, it is customary that they include the above mentioned functions. The same holds more and more often for insurance companies.

The existing literature on financial alliances is strongly concentrated around alliances created by cross-sector ownership (see, for the survey, Voutilainen [2004]). Our intention is to find out if ownership really is superior to looser alliance models.

In this paper, we have studied alliances between one or several banks and one or several insurance companies. We concentrate on the retail market although alliance formation also has significance in relation to other customer segments. The point of view is managerial assuming that a manager is willing to maximize share-holders' value. The additional assumption is important, because the manager might also have some personal criteria not compatible with the criteria of the share-holders. A supervisor's or a customer's perspective might be other alternative ways to consider the problem. These perspectives are only implicitly included in our considerations. 
The problem is formulated as a multiple criteria decision making task. In the first phase, we defined six different possible structure models for financial alliances and nine criteria used to evaluate the models. The models and the criteria were introduced together with bank and insurance experts. Each expert was interviewed individually. The experts are representatives of the top management of Finnish banks and insurance companies. In the second phase, the same experts were used as a panel to find the most preferred model for a financial alliance. As a decision support system we used the Analytic Hierarchy Process (AHP) developed by Saaty [1980] during the 70's. Currently, the AHP is a widely-known and used standard method for solving multiple criteria evaluation problems. Typically such problems consist of few alternatives and several criteria, possibly having a hierarchical structure. The AHP is a straightforward and transparent method that is also able to consider subjective and judgmental information.

Although the number of the applications of the AHP is numerous, it has not been applied much to financial problems (Steuer and Na [2003]). Among the four examples that Steuer and Na mention, Arbel and Orgler [1990] and Ossadnik [1996] are relevant with respect to this paper. Arbel and Orgler [1990] apply the AHP to the mergers and acquisitions process of a bank (targets are other banks), and they conclude that the AHP methodology can be applied to other complex and ill-defined strategic issues faced by banks. Ossadnik [1996] uses the AHP to allocate synergy to the partners in a merger, not necessarily between financial enterprises. Among the substantial amount of AHP applications it is difficult to find financial alliance related decision problems.

The paper is organized as follows. Section 2 describes our decision alternatives and criteria. In Section 3, we provide a brief introduction to the AHP and describe our problem by using the AHP presentation. Section 4 presents a decision making process and the results of the experts' meetings, our experiment, and the results. Finally, in Section 5, we conclude the paper with general remarks and ideas for further research.

\section{Structure Models for Financial Alliances and Evaluation Criteria}

\subsection{Structure Models}

Alliance structures can be classified in three main categories according to the degree of closeness of the members (see, for more details, Voutilainen [2004]). The categories in the increasing order of closeness are

Cross-selling agreements. The parties agree to sell each other's products to their own customers. The cross-selling is frequently one-sided. Most often a bank sells an insurance company's products to its customers. In principle, it could be vice versa as well. The alliance category can still be divided into two subcategories depending on whether the parties' service channels are overlapping or not. Non-overlapping service channels can be achieved, for 
example, if the parties actively try to organize cross-selling in such a way that there is no competition between the parties.

Here a service channel can be a branch office network, but also a call center, website etc. Especially in the case of overlapping branch networks one easily faces channel conflict: the alliance members do not co-operate effectively in the fear of losing their customers to the other party and consequently the sales provisions etc. Non-overlapping service channels often means that the other party has no service channel at all.

Thus the two different sub-models are

Cross-selling agreement, no overlapping service channels
(abbreviated CSA1)
Cross-selling agreement, overlapping service channels (CSA2)

Alliance of independent partners. The alliance type is a special case of a cross-selling agreement where the alliance is tightened by cross-ownership and/or joint ownership in third parties. Cross-ownership means a minority stake of the other party's shares. If the ownership were one-sided, it would probably be a sign of asymmetry and one party's dominance of the alliance. An example of joint ownership is a mutual fund management company owned jointly by a bank (banks) and an insurance company (insurance companies). One could also think about cross-ownership/joint ownership without a crossselling agreement, but such a model seldom occurs in practice.

The degree of overlapping is also used to divide this category into two different sub-models:
- $\quad$ Alliances of independent partners, no overlapping service channels (AIP1)
Alliances of independent partners, overlapping service channels (AIP2)

Control by ownership. In both the previous models, earnings and costs are divided. The third category means the model, where all the control is in the hand of one party: a bank can simply own (a control of) an insurance company or vice versa, or a third party owns the both ones.

This category is divided into two sub-models depending on the controller:

- Control by ownership, when a bank owns an insurance company or vice versa (CBO1)

- Control by ownership (financial conglomerate): a holding company owns one or several banks and one or several insurance companies (FC)

We can notice that the classification of the different alternatives is based on the closeness of the alliance and the degree of the overlapping of the service channels. 


\subsection{Evaluation Criteria}

The initial evaluation criteria for assessing the alliance models were introduced by combining our own knowledge with the opinions of the experts who were representatives of the top management of Finnish banks and insurance companies. To find the relevant criteria is an important task and crucial for the success of the decision making. Keeney and Raiffa [1976, p. 50], present the following desirable properties of the set of criteria:

- complete, it covers all the important aspects of the problem,

- operational, it can be meaningfully used in the analysis,

- decomposable, all aspects of the evaluation process can be simplified by breaking it down into parts,

- non redundant, so that the double counting of impacts can be avoided, and

- minimal, so that the problem dimension is kept as small as possible

Keeping these properties in our minds, we introduced the following nine criteria:

1. Product development (maximize efficiency),

2. One-door-principle (implement as effectively as possible),

3. Earnings logics (avoid conflicts),

4. Customer relationship management (maximize efficiency),

5. Cost and revenue synergies (maximize),

6. Channel conflicts (minimize),

7. Required solvency capital (optimize the balance),

8. Investor power (maximize),

9. Sales management (maximize efficiency).

Voutilainen [2004] provides a detailed description of the criteria and their background theories. A brief overview is given as follows:

\section{Product development}

Capability to develop new - especially hybrid - products is essential for any financial institution, and various alliances provide different possibilities for this activity.

\section{One-door-principle}

One-door-principle means that a customer is offered as many bank and insurance products at one place during one customer service event. The objective is full customer service at one stop and, thus, again packaging different products together and deepening customer relation.

\section{Earnings logics}

In an alliance, partners have to fit together their earnings logics. It is obvious that various alliance models provide different possibilities to define earnings logics. If no alliance member can control earnings logics, it may cause conflicts between alliance members. 
4. Customer relationship management

Customer-orientation means that a customer's needs are a key-issue for business. Customer relationship management (CRM) requires significant IT investments and continuous development. To reach agreement in development activities is necessary for successful business. The alliance CRM can be at least partially integrated.

\section{Cost and revenue synergies}

Scale benefits are obvious in the production of many financial products. They have traditionally been utilized by means of consolidation within the banking/insurance sectors. Cross-sector utilization most often requires consolidation, too.

\section{Channel conflicts}

A channel conflict occurs, when the alliance members compete for the same customers. It is important to develop a model where the channel conflicts are minimized.

\section{Solvency capital}

The return on equity (ROE) is one of the most important performance measures in financial enterprises. Therefore, company management must carefully optimize the relation between working capital and balance sheet.

\section{Investor power}

If two companies are consolidated, the investor power is often more than doubled because certain fixed minority limits may be exceeded. Conflicting interests may, on the other hand, prevent the implementation of rational investment plans.

\section{Sales management.}

Centralized sales management obviously requires centralized organizational structure, i.e. consolidation. On the other hand, some partners with a plain cross-selling agreement claim that they have succeeded in creating a very effective "cross-selling culture".

\section{Problem Formulation}

\subsection{Analytic hierarchy process}

Choosing the most preferred alliance structure is a typical multiple criteria evaluation problem. Six alternatives presented in sub-section 2.1 are evaluated using the nine criteria introduced in sub-section 2.2. We shall use the Analytic Hierarchy Process (AHP) by Saaty [1980] as a decision support system to solve the problem. The AHP provides us with a simple tool first to evaluate the mutual importance of the criteria, then to compare the alternative alliance structures on each criterion, and finally to synthesize the results onto one scale. 
The basic assumption in the Analytic Hierarchy Process (AHP) is that a human being makes comparisons between objects on a ratio scale (see, e.g. Saaty [1980]). For instance, the expression: $A$ is "twice better" than $B$ means that the utility (value) $v(A)$ of $A$ is two times higher than the utility (value) $v(B)$ of $B$. Even a "softer" expression like $A$ is "much better" than $B$ is interpreted in the AHP to mean that $v(A)=k v(B)$, where $k>>1$. It does not matter, whether the objects are concrete or abstract. It is easy to believe that a human being compares the weight of stones on a ratio scale, but not all researchers agree that, for example, the expression: "today it is much warmer than yesterday" can be evaluated on a ratio scale. Actually, it is quite plausible that even in this case people make a comparison on a ratio scale presenting their internal value scores for different temperatures. The scale naturally depends at least on the person making the comparison and on the time.

A central element in the AHP is a full set of $n(n-1) / 2$ pairwise comparisons, where $\mathrm{n}$ is the number of objects. Because it is difficult for a person to distinguish simultaneously more than 7-9 different levels of preference, Saaty (see, e.g. Saaty [1980, p. 54]) has proposed the use of the following verbal descriptions and the corresponding scores in making comparison:

Table 1: Verbal descriptions and the corresponding original numerical scores

\begin{tabular}{|l|l|l|}
\hline Score & Description & Explanation \\
\hline 1 & $\begin{array}{l}\text { Two activities contribute equally to the } \\
\text { objective }\end{array}$ \\
\hline 3 & $\begin{array}{l}\text { moderate importance of one } \\
\text { over other }\end{array}$ & $\begin{array}{l}\text { Experience and judgement slightly favor one } \\
\text { activity over another }\end{array}$ \\
\hline 5 & essential or strong importance & $\begin{array}{l}\text { Experience and judgement strongly favor } \\
\text { one activity over another }\end{array}$ \\
\hline 9 & demonstrated importance & $\begin{array}{l}\text { An activity is favored very strongly over } \\
\text { another; its dominance is demonstrated in } \\
\text { practice }\end{array}$ \\
\hline $2,4,6,8$ & $\begin{array}{l}\text { The evidence favoring one activity over } \\
\text { another is of the highest possible order of } \\
\text { affirmation. }\end{array}$ \\
\hline
\end{tabular}

If object $i$ has one of the above nonzero numbers assigned to it, when compared with object $\mathrm{j}$, then $\mathrm{j}$ has the reciprocal value when compared with $\mathrm{i}$. Intermediate scores of 2, 4, 6, and 8 are used, if a person thinks that for example object $i$ is at least moderately better than object $j$, but (s)he is not comfortable with saying that $i$ is strongly better than $j$, then his or her view might be represented by the score 4 . If object $j$ is at least moderately but not necessarily strongly better than object $i$, then the score $1 / 4$ would be assigned to the comparison of $i$ with $j$. As a result of pairwise comparisons, the following matrix is obtained: 


$$
A==\left(\begin{array}{cccc}
1 & a_{12} & \ldots & a_{1 n} \\
1 / a_{12} & 1 & \ldots & a_{2 n} \\
& & \ldots & \\
1 / a_{1 n} & 1 / a_{2 n} & \ldots & 1
\end{array}\right)
$$

Having recorded the quantified comparisons on pairs $i$ and $j$ as numerical entries in the matrix $A$, the problem now is to find numerical value scores $w_{i}, i$ $=1,2, \ldots, \mathrm{n}$, for objects such that $\mathrm{a}_{\mathrm{ij}} \approx \mathrm{w}_{\mathrm{i}} / \mathrm{w}_{\mathrm{j}}$. However, in practice, it is unrealistic to expect this relation to be exact. Part of the deviation is caused by the score used for $a_{i j}$, but the main part of the deviation is caused by the inability of a human being to be precisely knowledgeable and consistent. For example, if one prefers object 1 to object 2 by $2: 1$, and object 2 to object 3 by $3: 1$, consistency means that one should prefer object 1 to object 3 by $6: 1$, otherwise the comparison is inconsistent. Saaty [1994] provides some measures for evaluating the degree of inconsistency.

When the objects $i$ and $j$ are compared in a pairwise manner, one hopes that the final values derived from the paired comparisons of the objects are better than those obtained by direct assignment of numbers to all objects at once. How good the estimates are for value scores depends on the scale used to interpret verbal descriptions referring to the ratios of the value scores.

To estimate the value scores $w_{i}, i=1,2, \ldots, n$, on the basis of the pairwise comparison matrix, Saaty [1980, pp. 49-53] proposed the use of the eigenvalue method. As discussed in Saaty and Vargas [1984], other estimation criteria, such as least squares or logarithmic least squares, are also proposed in the literature.

An ultimate goal in the AHP, is to estimate a vector $w=\left(w_{1}, w_{2}, \ldots, w_{n}\right), w_{i}>$ $0, \mathrm{i}=1,2, \ldots, \mathrm{n}$, which usually is scaled such that $\Sigma_{\mathrm{i}} \mathrm{w}_{\mathrm{i}}=1$ whereby $\mathrm{w}_{\mathrm{i}}$ represents the relative value score of object $i$. The positivity condition $w_{i}>0$ on the components of the vector $w$ require that the objects be comparable on a ratio scale.

The objects to be compared may be for instance forces, actors, criteria (objectives) or alternatives (scenarios). In the AHP, the evaluation problem is presented in a hierarchy. At each hierarchy level, we have the objects of the same type. For instance, at the criterion level, we compare the criteria. At the lower level in the hierarchy, we may have the alternatives which are compared on each criterion.

\subsection{Alliance structure evaluation hierarchy}

The hierarchy of our problem is simple. In addition to the top level

"Attractiveness", we have only two levels. In many problems, the criteria have a hierarchical structure as well, but in our problem, the criteria C1, C2, .., C9 are all at the same level. The numbers in the hierarchy below refer to the criteria and the alliance structure alternatives are at the lowest level in the order CBO1, FC, AIP1, AIP2, CSA1, and CSA2. 


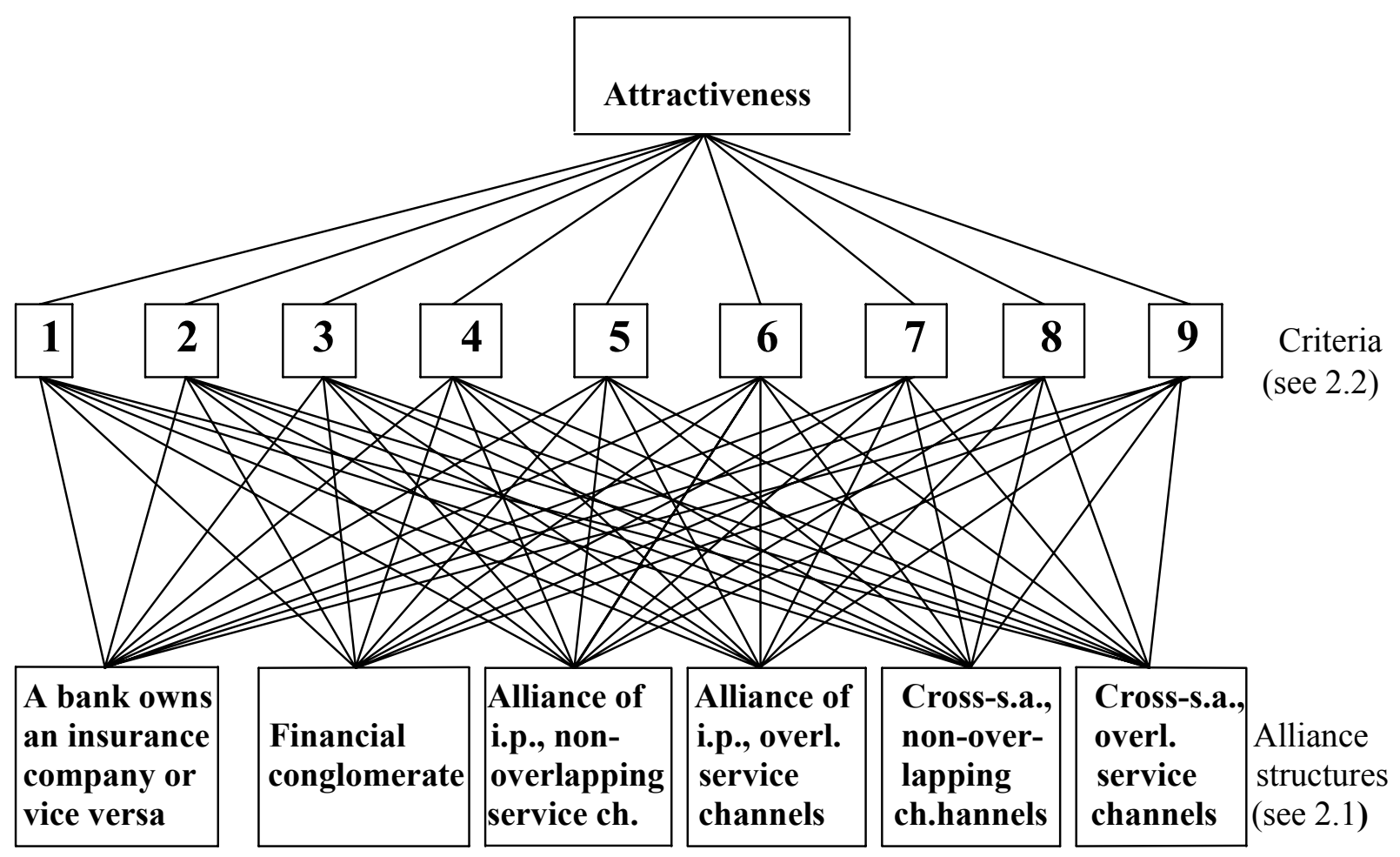

Figure 1. Alliance Structure Evaluation Hierarchy.

\section{Evaluation Process and Results}

\subsection{First Meeting}

Our expert panel consisted of eight experts from banks and insurance companies. Those experts were a subgroup of the group which we interviewed in structuring the problem. The participants did not know the method beforehand, therefore an example on the areas of some geometric figures was used as an introduction to the AHP. After the short introduction, we agreed about the decision making process. When a group is a decision maker, there are two different methods to be applied. Each group member can make his/her own evaluations, and then an external facilitator makes a synthesis of the evaluations. Another way is to ask the group to make comparisons as a group. To find the joint opinion, the group may apply a majority rule or a consensus principle. Our group decided to negotiate until reaching a consensus.

The group had a preliminary discussion about the semantics of the criteria to ensure a common perception. The members of the group were experienced 
professionals, and thus there were no difficulties in interpreting the criteria. As mentioned above, we discussed the criteria beforehand with each member.

The group started the evaluation process by comparing pairwise the mutual importance of the criteria. The importance was interpreted as a strength of the focus. (Unfortunately, the more precise definition is difficult to give.)

Table 2: The pairwise comparisons of the criteria

\begin{tabular}{|l|r|r|r|r|r|r|r|r|r|}
\hline Criteria & C1 & C2 & C3 & C4 & C5 & C6 & C7 & C8 & C9 \\
\hline C1 Product development & 1 & 0.333 & 0.143 & 0.167 & 0.125 & 0.143 & 0.143 & 3 & 0.167 \\
\hline C2 One-door-principle & 3 & 1 & 0.2 & 0.143 & 0.125 & 0.2 & 0.2 & 5 & 0.2 \\
\hline C3 Earnings logics & 7 & 5 & 1 & 2 & 0.2 & 4 & 3 & 9 & 4 \\
\hline C4 Customer relationship management & 6 & 7 & 0.5 & 1 & 0.143 & 0.333 & 0.25 & 8 & 1 \\
\hline C5 Cost and revenue synergies & 8 & 8 & 5 & 7 & 1 & 5 & 7 & 9 & 6 \\
\hline C6 Channel conflicts & 7 & 5 & 0.25 & 3 & 0.2 & 1 & 2 & 9 & 3 \\
\hline C7 Solvency capital & 7 & 5 & 0.333 & 4 & 0.143 & 0.5 & 1 & 9 & 0.333 \\
\hline C8 Investor power & 0.333 & 0.2 & 0.111 & 0.125 & 0.111 & 0.111 & 0.111 & 1 & 0.111 \\
\hline C9 Sales management. & 6 & 5 & 0.25 & 1 & 0.167 & 0.333 & 3 & 9 & 1 \\
\hline
\end{tabular}

By solving the eigenvalue problem of the matrix consisting of the pairwise comparisons to evaluate the mutual importance of the criteria, we will find the value score (priority) vector for the criteria. We standardize the vector by summing its element to one:

$$
w=(0.018,0.028,0.180,0.073,0.384,0.122,0.092,0.012,0.090)^{\top} .
$$

The consistency ratio CR (cf. Saaty [1994], pp. 84-85) was 0.138 . If the consistency ratio is below 0.10 , it is fully acceptable. However, the value 0.138 is clearly less than the unacceptable level 0.20 .

Next the group compared the various alliance models on each criterion.

Because the value scores of criterion $\mathrm{C} 1=0.018$ (Product development) and $\mathrm{C} 8=0.012$ (Investor power) were very low, their effect is very insignificant to the final composite score. That's why we drop them from further analysis. The results of pairwise comparisons and the corresponding value scores are given below:

\begin{tabular}{l|cccccc}
$\mathrm{C}_{2}$ & CBO1 & FC & AIP1 & AIP2 & CSA1 & CSA2 \\
\hline CBO1 & 1 & 1 & 3 & 7 & 4 & 8 \\
FC & 1 & 1 & 3 & 7 & 4 & 8 \\
AIP1 & 0.333 & 0.333 & 1 & 5 & 3 & 6 \\
AIP2 & 0.143 & 0.143 & 0.200 & 1 & 0.333 & 3 \\
CSA1 & 0.250 & 0.250 & 0.333 & 3 & 1 & 3 \\
CSA2 & 0.125 & 0.125 & 0.167 & 0.333 & 0.333 & 1
\end{tabular}

$v_{2}=(0.334,0.334,0.170,0.047,0.086,0.030)^{\top}, C R=0.042$. 


\begin{tabular}{l|cccccc}
$\mathrm{C}_{3}$ & CBO1 & FC & AIP1 & AIP2 & CSA1 & CSA2 \\
\hline CBO1 & 1 & 0.200 & 5 & 7 & 6 & 8 \\
FC & 5 & 1 & 7 & 9 & 8 & 9 \\
AIP1 & 0.200 & 0.143 & 1 & 3 & 3 & 5 \\
AIP2 & 0.143 & 0.111 & 0.333 & 1 & 0.333 & 2 \\
CSA1 & 0.167 & 0.125 & 0.333 & 3 & 1 & 3 \\
CSA2 & 0.125 & 0.111 & 0.200 & 0.500 & 0.333 & 1
\end{tabular}

$v_{3}=(0.251,0.531,0.097,0.036,0.059,0.026)^{\top}, C R=0.093$.

\begin{tabular}{l|cccccc}
$\mathrm{C}_{4}$ & CBO1 & FC & AIP1 & AIP2 & CSA1 & CSA2 \\
\hline CBO1 & 1 & 1 & 6 & 6 & 7 & 7 \\
FC & 1 & 1 & 6 & 6 & 7 & 7 \\
AIP1 & 0.167 & 0.167 & 1 & 1 & 3 & 3 \\
AIP2 & 0.167 & 0.167 & 1 & 1 & 3 & 3 \\
CSA1 & 0.143 & 0.143 & 0.333 & 0.333 & 1 & 1 \\
CSA2 & 0.143 & 0.143 & 0.333 & 0.333 & 1 & 1
\end{tabular}

$v_{4}=(0.375,0.375,0.086,0.086,0.039,0.039)^{\top}, C R=0.032$.

\begin{tabular}{l|cccccc} 
C $_{5}$ & CBO1 & FC & AIP1 & AIP2 & CSA1 & CSA2 \\
\hline CBO1 & 1 & 0.500 & 6 & 8 & 7 & 9 \\
FC & 2 & 1 & 7 & 9 & 8 & 9 \\
AIP1 & 0.167 & 0.143 & 1 & 3 & 2 & 4 \\
AIP2 & 0.125 & 0.111 & 0.333 & 1 & 2 & 4 \\
CSA1 & 0.143 & 0.125 & 0.500 & 0.500 & 1 & 3 \\
CSA2 & 0.111 & 0.111 & 0.250 & 0.250 & 0.333 & 1
\end{tabular}

$v_{5}=(0.331,0.448,0.091,0.059,0.047,0.026)^{\top}, C R=0.068$.

\begin{tabular}{l|cccccc}
$\mathrm{C}_{6}$ & CBO1 & FC & AIP1 & AIP2 & CSA1 & CSA2 \\
\hline CBO1 & 1 & 1 & 1 & 7 & 1 & 9 \\
FC & 1 & 1 & 1 & 7 & 1 & 9 \\
AIP1 & 1 & 1 & 1 & 7 & 1 & 9 \\
AIP2 & 0.143 & 0.143 & 0.143 & 1 & 0.143 & 2 \\
CSA1 & 1 & 1 & 1 & 7 & 1 & 9 \\
CSA2 & 0.111 & 0.111 & 0.111 & 0.500 & 0.111 & 1
\end{tabular}

$v_{6}=(0.235,0.235,0.235,0.036,0.235,0.024)^{\top}, C R=0.004$. 


\begin{tabular}{l|cccccc} 
C $_{7}$ & CBO1 & FC & AIP1 & AIP2 & CSA1 & CSA2 \\
\hline CBO1 & 1 & 0.333 & 6 & 6 & 8 & 8 \\
FC & 3 & 1 & 7 & 7 & 9 & 9 \\
AIP1 & 0.167 & 0.143 & 1 & 1 & 3 & 3 \\
AIP2 & 0.167 & 0.143 & 1 & 1 & 3 & 3 \\
CSA1 & 0.125 & 0.111 & 0.333 & 0.333 & 1 & 1 \\
CSA2 & 0.125 & 0.111 & 0.333 & 0.333 & 1 & 1
\end{tabular}

$v_{7}=(0.301,0.483,0.075,0.075,0.033,0.033)^{\top}, C R=0.042$.

\begin{tabular}{l|cccccc} 
C9 & CBO1 & FC & AIP1 & AIP2 & CSA1 & CSA2 \\
\hline CBO1 & 1 & 0.333 & 5 & 7 & 6 & 8 \\
FC & 3 & 1 & 6 & 8 & 7 & 9 \\
AIP1 & 0.200 & 0.167 & 1 & 4 & 2 & 5 \\
AIP2 & 0.143 & 0.125 & 0.250 & 1 & 0.333 & 2 \\
CSA1 & 0.167 & 0.143 & 0.500 & 3 & 1 & 3 \\
CSA2 & 0.125 & 0.111 & 0.200 & 0.500 & 0.333 & 1
\end{tabular}

$v_{9}=(0.292,0.470,0.105,0.038,0.068,0.028)^{\top}, C R=0.064$.

A composite value scale for the alliance structure alternatives is found by computing the weighted sums for each alternative. The separate value scores are multiplied by the re-scaled scores of the criteria. After dropping two criteria, the rest elements are scaled to sum up to one.

Table 3: The composite priority vector for the alliance structure models

\begin{tabular}{|l|r|r|r|r|r|r|r|r|}
\hline & \multicolumn{1}{|c}{ C2 } & \multicolumn{1}{c}{ C3 } & \multicolumn{1}{c}{ C4 } & C5 & \multicolumn{1}{c|}{ C6 } & \multicolumn{1}{c|}{ C7 } & \multicolumn{1}{c|}{ C9 } & \\
\hline & $\mathbf{0 . 0 2 9}$ & $\mathbf{0 . 1 8 6}$ & $\mathbf{0 . 0 7 5}$ & $\mathbf{0 . 3 9 6}$ & $\mathbf{0 . 1 2 6}$ & $\mathbf{0 . 0 9 4 9}$ & $\mathbf{0 . 0 9 3}$ & $\Sigma$ \\
\hline CBO1 & 0.334 & 0.251 & 0.375 & 0.331 & 0.235 & 0.301 & 0.292 & $\mathbf{0 . 3 0 1}$ \\
\hline FC & 0.334 & 0.531 & 0.375 & 0.448 & 0.235 & 0.483 & 0.47 & $\mathbf{0 . 4 3 3}$ \\
\hline AIP1 & 0.17 & 0.097 & 0.086 & 0.091 & 0.235 & 0.075 & 0.105 & $\mathbf{0 . 1 1 2}$ \\
\hline AIP2 & 0.047 & 0.036 & 0.086 & 0.059 & 0.036 & 0.075 & 0.038 & $\mathbf{0 . 0 5 3}$ \\
\hline CSA1 & 0.086 & 0.059 & 0.039 & 0.047 & 0.235 & 0.033 & 0.068 & $\mathbf{0 . 0 7 4}$ \\
\hline CSA2 & 0.03 & 0.026 & 0.039 & 0.026 & 0.024 & 0.033 & 0.028 & $\mathbf{0 . 0 2 8}$ \\
\hline
\end{tabular}

Control by ownership is strongly preferred on all chosen criteria. It can also be observed that in other models separate service channels yield higher priority values than cross-ownership or joint ownership: AIP1 > CSA1 > AIP2 > CSA2. 


\subsection{Second Meeting}

The group of experts experienced the approach very useful and interesting and expressed their wish to re-consider the problem in a later session. In the second session about a month later on, we reported the results of the first meeting and continued discussions. Especially, the group further discussed the reasons why the priorities of criterion $\mathrm{C} 1=0.018$ (Product development), C2 $=0.028$ (One Door-Principle) and C8 $=0.012$ (Investor power) were very low, even if they initially seemed to be important. We already dropped $\mathrm{C} 1$ and C8 from further analysis, but the group discussed what to do with criterion C2. The group decided to drop it as well. Even if it is important, it is redundant. The same aspects are considered with the other criteria.

Furthermore, after re-consideration the group concluded that some of the important evaluation criteria were still missing from the criterion set. The Finnish financial corporations seek for economies of scale or critical mass to be able to defend themselves against the liberalized EU competition. Of course, they also want to strengthen their market position against their domestic competitors. The group decided to introduce two new criteria:

\section{Economies of scale}

The criterion refers to the scale benefits of the business processes.

\section{Economies of scope}

This criterion speaks about effectivizing the customer management and enlarging the product portfolio and thereby maximizing "share of wallet" by, for example, effective cross-selling.

The group also noticed that risk management aspects were totally overlooked and decided to take risk into considerations as well:

\section{Risk}

Different alliance structure models have different possibilities to fail. The objective of business generally is to find the alternative to minimize the negative effects caused by risk.

The pairwise comparisons with the revised set of criteria are given in Table 4 . 
Table 4: Pairwise comparison of the revised set of criteria

\begin{tabular}{|l|r|r|r|r|r|r|r|r|r|}
\hline Criteria & C3 & C4 & C5 & C6 & C7 & C9 & C10 & C11 & C12 \\
\hline 3. Earnings logics & 1 & 2 & 0.25 & 4 & 3 & 4 & 0.333 & 0.167 & 5 \\
\hline 4. Customer relationship management & 0.5 & 1 & 0.143 & 0.333 & 0.25 & 1 & 0.167 & 0.111 & 0.333 \\
\hline 5. Cost and revenue synergies & 4 & 7 & 1 & 5 & 7 & 6 & 0.5 & 0.2 & 4 \\
\hline 6. Channel conflicts & 0.25 & 3 & 0.2 & 1 & 2 & 3 & 0.2 & 0.143 & 3 \\
\hline 7. Solvency capital & 0.333 & 4 & 0.143 & 0.5 & 1 & 0.5 & 0.25 & 0.125 & 0.5 \\
\hline 9. Sales management. & 0.25 & 1 & 0.167 & 0.333 & 2 & 1 & 0.2 & 0.111 & 0.25 \\
\hline 10. Economy of scale & 3 & 6 & 2 & 5 & 4 & 5 & 1 & 0.25 & 4 \\
\hline 11. Economy of scope & 6 & 9 & 5 & 7 & 8 & 9 & 4 & 1 & 7 \\
\hline 12. Risk & 0.2 & 3 & 0.25 & 0.333 & 2 & 4 & 0.25 & 0.143 & 1 \\
\hline
\end{tabular}

The value scale for criteria is as follows:

$$
\mathrm{w}=(0.094,0.023,0.169,0.054,0.033,0.027,0.172,0.383,0.046)^{\mathrm{T}}
$$

The consistency ratio CR was 0.101 . The model prioritizations corresponding to the new criteria became

\begin{tabular}{l|cccccc}
$\mathrm{C}_{10}$ & CBO1 & FC & AIP1 & AIP2 & CSA1 & CSA2 \\
\hline CBO1 & 1 & 1 & 5 & 7 & 7 & 9 \\
FC & 1 & 1 & 5 & 7 & 7 & 9 \\
AIP1 & 0.200 & 0.200 & 1 & 3 & 3 & 5 \\
AIP2 & 0.143 & 0.143 & 0.333 & 1 & 1 & 3 \\
CSA1 & 0.143 & 0.143 & 0.333 & 1 & 1 & 3 \\
CSA2 & 0.111 & 0.111 & 0.200 & 0.333 & 0.333 & 1
\end{tabular}

$v_{10}=(0.374,0.374,0.117,0.054,0.054,0.027)^{\top} . C R=0.036$.

\begin{tabular}{l|cccccc} 
C $11_{11}$ & CBO1 & FC & AIP1 & AIP2 & CSA1 & CSA2 \\
\hline CBO1 & 1 & 1 & 3 & 6 & 4 & 7 \\
FC & 1 & 1 & 3 & 6 & 4 & 7 \\
AIP1 & 0.333 & 0.333 & 1 & 3 & 3 & 5 \\
AIP2 & 0.167 & 0.167 & 0.333 & 1 & 1 & 3 \\
CSA1 & 0.250 & 0.250 & 0.333 & 1 & 1 & 3 \\
CSA2 & 0.143 & 0.143 & 0.200 & 0.333 & 0.333 & 1
\end{tabular}

$v_{11}=(0.335,0.335,0.157,0.066,0.075,0.034)^{\top} . C R=0.028$. 


\begin{tabular}{l|cccccc} 
C $_{12}$ & CBO1 & FC & AIP1 & AIP2 & CSA1 & CSA2 \\
\hline CBO1 & 1 & 1 & 0.333 & 0.333 & 0.200 & 0.200 \\
FC & 1 & 1 & 0.333 & 0.333 & 0.200 & 0.200 \\
AIP1 & 3 & 3 & 1 & 1 & 0.333 & 0.333 \\
AIP2 & 3 & 3 & 1 & 1 & 0.333 & 0.333 \\
CSA1 & 5 & 5 & 3 & 3 & 1 & 1 \\
CSA2 & 5 & 5 & 3 & 3 & 1 & 1
\end{tabular}

$v_{12}=(0.052,0.052,0.129,0.129,0.318,0.318)^{\top} . C R=0.012$.

Table 5: The composite priority vector

\begin{tabular}{|l|c|c|c|c|c|c|c|c|c|c|}
\hline & C3 & C4 & C5 & C6 & C7 & C9 & C10 & C11 & C12 & \\
\hline & $\mathbf{0 . 0 9 4}$ & $\mathbf{0 . 0 2 3}$ & $\mathbf{0 . 1 6 9}$ & $\mathbf{0 . 0 5 4}$ & $\mathbf{0 . 0 3 3}$ & $\mathbf{0 . 0 2 7}$ & $\mathbf{0 . 1 7 2}$ & $\mathbf{0 . 3 8 3}$ & $\mathbf{0 . 0 4 6}$ & $\boldsymbol{\Sigma}$ \\
\hline CBO1 & 0.251 & 0.375 & 0.331 & 0.235 & 0.301 & 0.292 & 0.374 & 0.335 & 0.052 & $\mathbf{0 . 3 1 4}$ \\
\hline FC & 0.531 & 0.375 & 0.448 & 0.235 & 0.483 & 0.47 & 0.374 & 0.335 & 0.052 & $\mathbf{0 . 3 7 1}$ \\
\hline AIP1 & 0.097 & 0.086 & 0.091 & 0.235 & 0.075 & 0.105 & 0.117 & 0.157 & 0.129 & $\mathbf{0 . 1 3 1}$ \\
\hline AIP2 & 0.036 & 0.086 & 0.059 & 0.036 & 0.075 & 0.038 & 0.054 & 0.066 & 0.129 & $\mathbf{0 . 0 6 1}$ \\
\hline CSA1 & 0.059 & 0.039 & 0.047 & 0.235 & 0.033 & 0.068 & 0.054 & 0.075 & 0.318 & $\mathbf{0 . 0 8 3}$ \\
\hline CSA2 & 0.026 & 0.039 & 0.026 & 0.024 & 0.033 & 0.028 & 0.027 & 0.034 & 0.318 & $\mathbf{0 . 0 4 3}$ \\
\hline
\end{tabular}

All the criteria but risk describe financial aspects of business. When risk is evaluated together with other criteria, its weight is only $4.6 \%$ of the total sum of weights. In fact, its weight is about $12 \%$ of the weight of the most important financial criterion Economies of scope. For this reason, we extract risk from the set of the criteria, and rescale the criteria. The composite priority vector is in Table 6.

Table 6: The composite priority vector without the risk criterion

\begin{tabular}{|l|c|c|c|c|c|c|c|c|c|}
\hline & C3 & C4 & C5 & \multicolumn{1}{c|}{ C6 } & \multicolumn{1}{c|}{ C7 } & \multicolumn{1}{c|}{ C9 } & C10 & C11 & \\
\hline & $\mathbf{0 . 0 8 4}$ & $\mathbf{0 . 0 2 5}$ & $\mathbf{0 . 1 7 6}$ & $\mathbf{0 . 0 5}$ & $\mathbf{0 . 0 3 7}$ & $\mathbf{0 . 0 3 2}$ & $\mathbf{0 . 1 8}$ & $\mathbf{0 . 4 1 5}$ & $\Sigma$ \\
\hline CBO1 & 0.251 & 0.375 & 0.331 & 0.235 & 0.301 & 0.292 & 0.374 & 0.335 & $\mathbf{0 . 3 2 7}$ \\
\hline FC & 0.531 & 0.375 & 0.448 & 0.235 & 0.483 & 0.47 & 0.374 & 0.335 & $\mathbf{0 . 3 8 4}$ \\
\hline AIP1 & 0.097 & 0.086 & 0.091 & 0.235 & 0.075 & 0.105 & 0.117 & 0.157 & $\mathbf{0 . 1 3 0}$ \\
\hline AIP2 & 0.036 & 0.086 & 0.059 & 0.036 & 0.075 & 0.038 & 0.054 & 0.066 & $\mathbf{0 . 0 5 8}$ \\
\hline CSA1 & 0.059 & 0.039 & 0.047 & 0.235 & 0.033 & 0.068 & 0.054 & 0.075 & $\mathbf{0 . 0 7 0}$ \\
\hline CSA2 & 0.026 & 0.039 & 0.026 & 0.024 & 0.033 & 0.028 & 0.027 & 0.034 & $\mathbf{0 . 0 3 0}$ \\
\hline
\end{tabular}

We present the final results as a two-criteria evaluation model:

Table 7: The two-criteria final model

\begin{tabular}{|l|r|l|}
\hline & $\begin{array}{l}\text { Financial } \\
\text { Aspects }\end{array}$ & Risk \\
\hline CBO1 & 0.327 & 0.052 \\
\hline FC & 0.384 & 0.052 \\
\hline AIP1 & 0.130 & 0.129 \\
\hline AIP2 & 0.058 & 0.129 \\
\hline CSA1 & 0.070 & 0.318 \\
\hline CSA2 & 0.030 & 0.318 \\
\hline
\end{tabular}


We may present the alternatives as a two-dimensional figure below:

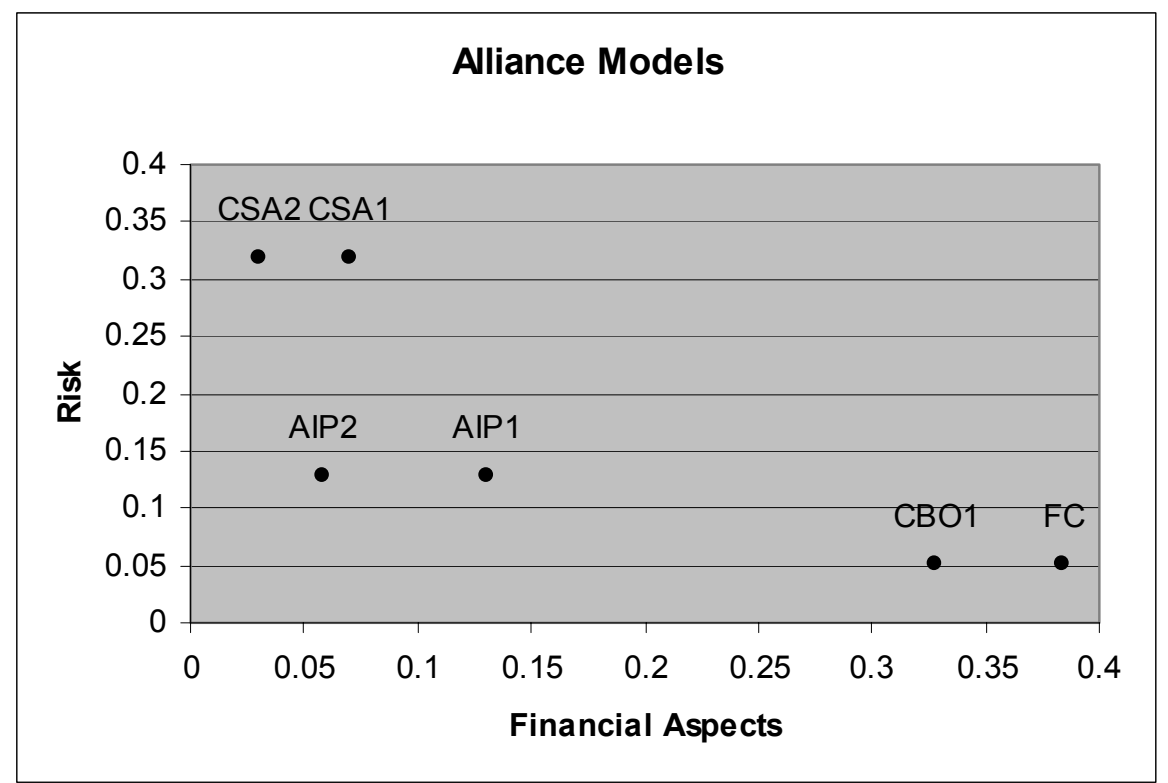

Figure 1: Alliance Models in the Two-Dimensional Criterion Space

From the Figure 1, we see that alternative CSA1 dominates CSA2, alternative AIP1 dominates AIP2, and alternative FC dominates CBO1. Because dominated solutions are not rational alternatives, we do not need to further consider them.

Assume a manager likes to introduce the final priority vector by weighting these two criteria. If a manager emphasizes the risk by giving a weight which is higher than 0.46 for risk and value less than 0.54 for the financial composite criterion, then the choice is always Cross-selling agreement, no overlapping service channels (CSA1). In the other case, the choice is Financial conglomerate (FC). Other choices are said to be convex-dominated, i.e. CSA1 or FC is always best no matter which weights are used. A risk-averse manager would prefer CSA1, while the choice of a risk-taker is FC. However, in case the value function is not linear, alternative AIP1 might be a feasible solution as well. Finally, if the decision-maker uses a max-min criterion, AIP1 is clearly the best alternative.

\section{Conclusion}

We have shown that the expert panel assisted by the AHP was a successful approach in searching for the most preferred alliance structure between banks and insurance companies. The use of the AHP focused the discussions on pairwise comparisons. The second meeting was the initiative of the panel. The panel members felt that the problem required more considerations.

During the second meeting the panel first evaluated critically original criteria and revised some of them. In addition, they realized that the risk was not considered at all. The panel preferred the control by ownership models (FC, 
CBO1). Actually, the FC (Financial conglomerate) was the most preferred. On the other hand, a risk-averse manager might also prefer CSA1 (Cross-selling agreement, no overlapping service channels) or even AIP1 (Alliance of independent partners, no overlapping service channels) to FC.

Even if the alliance models FC and CBO1 are preferable, they are not always feasible. It might be difficult to find partners, who are willing to develop these alliance structures. Furthermore, consolidation is impossible for most local banks and mutual insurance companies.

The presented computation model can be used by various financial companies in their alliance strategic development. The criteria can be prioritized at different levels of a company. It can be seen from table 3 that the alliance models FC and CBO1 are dominant with respect to all the financial criteria. Therefore, they shall retain their status as the two most preferrable alliance models whatever priorities the criteria are given.

In this paper, our point of view was that of the top management of a company considering an alliance. However, these problems are not only managerial. The perspectives of clients and supervisory authorities might also be investigated. These perspectives are topics for further research.

\section{Acknowledgements}

We would like to thank the following experts for their interest in the problem and participating in the two meetings in February and March, 2004.

\begin{tabular}{|c|c|c|}
\hline $\begin{array}{l}\text { J.-P. Halmeenmäki } \\
\text { Sepno llvessalo }\end{array}$ & $\begin{array}{l}\text { Managing director } \\
\text { Consultant }\end{array}$ & Tapiola Life Insurance \\
\hline Harri Kainulainen & Managing director & Local Insurance Group \\
\hline Matti Ruohonen & Managing director & Veritas Life Insurance \\
\hline Pauli Sarelius & Deputy managing dir. & Okobank Life Insurance \\
\hline Robert Sergelius & Deputy managing dir. & Aktia Savings Bank \\
\hline Timo Tuomenpuro & Chief strategist & Pohjola Insurance Group \\
\hline Markku Vesterinen & Deputy managing dir. & Suomi Life Insurance \\
\hline
\end{tabular}

We would also like to thank the MCDS seminar group of the Helsinki School of Economics for inspiring discussions, especially Professor Jyrki Wallenius, Doctor Lasse Koskinen and M.Sc. Leena Tanner.

\section{References}

Arbel, A., Orgler, Y. E. [1990], An application of the AHP to bank strategic planning: The mergers and acquisitions process, European Journal of Operational Research 48 (1990), pp. 27-37. 
Keeney, R. L. and Raiffa, H. [1976], Decisions with Multiple Objectives, Preferences and Value Tradeoffs, Cambridge University Press.

Ossadnik, W. [1996], AHP-based synergy allocation to the partners in a merger, European Journal of Operational Research 88, pp. 42-49.

Saaty, T. [1980], The Analytic Hierarchy Process - Planning, Priority Setting, Resource Allocation, McGraw-Hill, New York, USA.

Saaty, T. [1994], Fundamentals of decision making and priority theory with the analytic hierarchy process, Vol. VI, RWS publications, Pittsburgh, PA, USA.

Saaty, T. and Vargas, L. [1984], Comparison of eigenvalue, logarithmic least squares and least squares methods in estimating ratios. Mathematical Modelling 5, pp. 309-324.

Steuer, R. E., Na, P. [2003], Multiple criteria decision making combined with finance: A categorized bibliographic study, European Journal of Operational Research 150(3), pp. 496-515.

Voutilainen, R. [2004], Comparing alternative structures of financial alliances, Helsinki School of Economics, Working papers W-364. 